\title{
Nephrin loss is reduced by grape seed proanthocyanidins in the experimental diabetic nephropathy rat model
}

\author{
XIANHUA LI ${ }^{1}$, ZHAOLI GAO ${ }^{1}$, HAIQING GAO ${ }^{2}$, BAOYING $^{2}{ }^{2}$, TAO PENG $^{1}$, \\ BEI JIANG ${ }^{1}$, XIANGDONG YANG ${ }^{1}$ and $\mathrm{ZHAO} \mathrm{HU}^{1}$
}

Departments of ${ }^{1}$ Nephrology and ${ }^{2}$ Geriatrics, Qi Lu Hospital of Shandong University, Jinan, Shandong 250012, P.R. China

Received March 1, 2017; Accepted August 31, 2017

DOI: $10.3892 / \mathrm{mmr} .2017 .7837$

\begin{abstract}
Diabetic nephropathy (DN) is one of the major causes of end-stage renal failure. Grape seed proanthocyanidin extracts (GSPE) are known to act as antioxidants. The current study aimed to determine the effects of GSPE on the streptozotocin (STZ)-induced diabetic rat model and to explore the underlying mechanism of its action. Wistar rats were induced into a diabetic state by injection of STZ and were treated with $250 \mathrm{mg} \cdot \mathrm{kg}^{-1} \cdot \mathrm{day}^{-1} \mathrm{GSPE}$ for 24 weeks. Kidney samples were collected for observation of renal pathological changes by light microscope (periodic acid-Schiff staining) and electron microscopy. Reverse transcription-polymerase chain reaction, western blotting, and immunohistochemical staining were used to detect the mRNA and protein expression of the receptor for advanced glycation end-products (RAGE), nephrin and podocin. The results indicated that diabetic rats treated with GSPE had markedly reduced Ccr, urinary albumin excretion, ratio of kidney weight to body weight, AGEs and ECM accumulation $(\mathrm{P}<0.01)$ compared with that in the diabetic rats. GSPE treatment can also reverse the renal pathological damage in diabetic rats. Further results indicated that GSPE treatment significantly decreased the RAGE expression level $(\mathrm{P}<0.01)$, and significantly increased the expression level of nephrin in the kidney and glomeruli of diabetic rats $(\mathrm{P}<0.01)$. However, no significant differences were identified in the expression of podocin following GSPE treatment $(\mathrm{P}>0.05)$. In conclusion, the results demonstrated that GSPE exerts a reno-protective effect by decreasing urinary albumin excretion and reversing renal pathological damage in diabetic rats. The underlying mechanism of GSPE activity is associated with the decreased expression of the AGEs/RAGE axis and the increased expression of nephrin in diabetic rats.
\end{abstract}

Correspondence to: Professor Xianhua Li, Department of Nephrology, Qi Lu Hospital of Shandong University, 107 Wenhua Xi Road, Jinan, Shandong 250012, P.R. China

E-mail:1i_xianhua@sohu.com

Key words: diabetic nephropathy, nephrin, grape seed proanthocyanidins extracts

\section{Introduction}

Diabetic nephropathy (DN) is a major cause of end-stage renal failure and is one of the direct causes of mortality in diabetic patients $(1,2)$. In clinical terms, DN patients are commonly characterized by the development of proteinuria, specifically albuminuria, with a subsequent reduction in the glomerular filtration rate (2). Multitude pathological changes in the kidneys contribute to the progressive decline in renal function, including macrophages in filtration, extracellular matrix (ECM) accumulation in multiple renal cells, glomerular and tubular hypertrophy, endothelial dysfunction, mesangial cell expansion and podocyte injury (3). Identification of molecular changes associated with the pathophysiology of DN is imperative for the development of therapeutic strategies.

The loss of size-selective and/or charge-selective properties of the glomerular filtration barrier are reported to be responsible for the observed proteinuria in glomerular diseases. The glomerular filtration barrier is composed of three layers: A glomerular basement membrane (GBM), a fenestrated endothelial layer and podocyte foot processes that are connected by a slit diaphragm. Diaphragm-associated proteins podocin and nephrin (4) are crucial proteins in the complex of molecules that assemble and reinforce the slit diaphragm and serve central roles in maintaining the size-selective barrier $(5,6)$.

Advanced glycation end-products (AGEs) are biochemical end-products of nonenzymatic glycation (7). AGEs have been suggested to serve a vital role in the development of DN due to the fact that drugs that either break the AGE crosslink or inhibit AGE formation have been demonstrated to exhibit a protective effect on experimental DN (8). The structure and function of matrix tissue proteins can be altered by AGE modification, which thus stimulates a variety of cellular responses via a specific cell-surface receptor on glomerular cells (9). Importantly, the specific cellular receptor for AGE (RAGE) that is upregulated and activated by AGE (10), has been demonstrated to serve an important role in the development of DN (11). Therefore, the AGE-RAGE interaction likely serves an important role in the pathogenesis of DN (12-14).

GSPE is derived from grape seeds and possesses potent properties, such as radical scavenging, anti-inflammation, antioxidant, anti-tumor and cardiovascular protection activity (15). Previous studies demonstrate that GSPE can act in the prevention of multiple diseases such as cataracts, gastric 
ulcer, atherosclerosis, myocardial ischemia-reperfusion and especially diabetes (16-18). However, the function of GSPE on $\mathrm{DN}$ has been rarely studied. The aim of the current study was to determine the effect of GSPE on the streptozotocin-induced diabetic rat model and to explore the underlying mechanisms of its activity.

\section{Materials and methods}

Ethics statement. The current study was approved by the Animal Ethics Committee of Shandong University (Jinan, Shandong, China).

Animals. A total of 60 male Wistar rats (lot no. SCXL20030004; 6-7 weeks old; weight, 180-200 g) were obtained from the Shandong University Experimental Animal Center (Jinan, Shandong, China). These rats were housed in cages and allowed free access to food and tap water. They were maintained on a 12:12 h dark/light cycle, with a room temperature of $22 \pm 1.5^{\circ} \mathrm{C}$ and a humidity of $55 \pm 5 \%$. A total of 24 rats were selected randomly and divided into 2 groups ( $\mathrm{n}=12$ in each group), and the control group (C group) was treated with a dosage of $250 \mathrm{mg} \cdot \mathrm{kg}^{-1} \cdot \mathrm{day}^{-1} \mathrm{GSPE}$ (CT group) (lot no. G050412; Tianjin Jianfeng Natural Product R\&D Co., Ltd., Tianjin, China) (14). The remaining 36 rats were injected with a dose of $55 \mathrm{mg} \cdot \mathrm{kg}^{-1} \mathrm{STZ}$ (injected into the tail veins). After five days, rats with blood glucose levels higher than $16.7 \mathrm{mmol} / 1$ were considered as being diabetic, and six rats were excluded for failure to meet this criterion. One week after STZ injection, the diabetic rats were then divided randomly into 2 groups ( $\mathrm{n}=15$ in each group), a diabetic group without any treatment (diabetes mellitus; DM; group), and another diabetic group that was treated with a dosage of $250 \mathrm{mg} \cdot \mathrm{kg}^{-1} \cdot \mathrm{day}^{-1}$ GSPE (T group). The GSPE was intragastrically administrated in normal saline solution for 24 weeks. At the end of the experiments, the animals were fasted overnight for $18 \mathrm{~h}$ and then anesthetized with intraperitoneal injection of sodium pentobarbitone $(60 \mathrm{mg} / \mathrm{kg}$; Sigma-Aldrich; Merck KGaA, Darmstadt, Germany) and sacrificed. Kidneys were perfused with ice-cold PBS and then were stored at $-80^{\circ} \mathrm{C}$.

Assessment of renal function. At the end of the experiments, the fasting plasma glucose (FPG), $24 \mathrm{~h}$ urinary albumin excretion, hemoglobin $\mathrm{Alc}\left(\mathrm{HbA}_{1 \mathrm{C}}\right)$, urinary creatinine (Ucr), serum creatinine $(\mathrm{Scr}), \mathrm{Ccr}=\mathrm{Ucr} / \mathrm{ScrxV}(\mathrm{V}: \mathrm{ml} / \mathrm{min}$, urine per minute), and the ratio of kidney weight to bodyweight and serum AGEs was measured for each rat. Scr and Ucr were measured using an automatic biochemical analysis instrument (DVI 1650; Bayer AG, Leverkusen, Germany). $\mathrm{HbA}_{1 \mathrm{C}}$ was measured by high-pressure liquid phase methods (ADAMS A1c HA-8180; Arkray, Inc., Kyoto, Japan). The level of AGEs in serum was measured by the enzyme-linked immunosorbent assay (ELISA) method (19) (Hitachi 850; Hitachi, Tokyo, Japan). To collect urine samples, rats were placed in individual metabolic cages for $24 \mathrm{~h}$ prior to sacrificing. ELISA (Nephrat II; Exocell, Philadelphia, PA, USA) was used to determine $24 \mathrm{~h}$ urinary albumin excretion levels.

Light microscope examination. For the light microscopic examination, the kidneys were immersion-fixed, embedded and two sections (4 $\mu \mathrm{m}$ thickness) were stained with periodic acid-Schiff (PAS) reagent. For electron microscope examination, the renal cortex was cut into small pieces and pre-fixed in glutaraldehyde, post-fixed in buffered sodium tetroxide for $1 \mathrm{~h}$, and then embedded in EPON 812 embedding resin (Electron Microscopy Sciences, Fort Washington, PA, USA). The PAS-positive area present in the mesangial region excluding cellular elements indicated mesangial matrix expansion. By using Leica QWin version 3 image analysis software (Leica Microsystems $\mathrm{GmbH}$, Wetzlar, Germany), the percentage of the PAS-positive area in the glomerulus was analyzed. A total of 10 glomeruli, randomly selected in the two slides from the rats (a minimum of 8 rats in each group), were evaluated by two investigators blinded of the origins of the slides.

Electron microscope examination. For transmission electron microscopic examination, a JEOL JSM 1011 microscope (JEOL, Ltd., Tokyo, Japan), was used to photograph images covering one or two glomerular cross-sections. The images at x15,000 magnification were used to measure the GBM length and the number of slit pores. To determine the FPW (foot process width), the slit pore length, and the GBM thickness, the images at $\times 50,000$ or $\times 100,000$ magnification were used according to published methods (20-22).

Reverse transcription-polymerase chain reaction (RT-PCR). The total RNA was extracted from the renal cortex using TRIzol reagent (Thermo Fisher Scientific Inc., Waltham, MA, USA). Primers for RAGE, nephrin, podocin, and glyceraldehyde-3-phosphate dehydrogenase (GAPDH) were designed and synthesized (Huada Gene Center, Beijing, China) based on the published sequence. The primers were as follows: RAGE forward, 5'-GCTCTGACCGAAGCGTGA-3' and reverse, 5'-CCTTCAGGCTCAACCAACAG-3', 240 bp product; nephrin forward, 5'-ACCAAGTCCAGTCGCCCAG-3' and reverse, 5'-ATACCAGCCTCACCCGAGTCCC-3', 306 bp product; podocin forward, 5'-GTGTCCAAAGCCATCCAG TT-3' and reverse, 5'-GTCTTTGTGCCTCAGCTTCC-3', 232 bp product; and GAPDH forward, 5'-GAGGGGCCA TCCACAGTCTTCTG-3' and reverse, 5'-CCCTTCATTGAC CTCAACTACATGGT-3'. The Titan One Tube RT-PCR kit (Boehringer-Mannheim, Shanghai, China) was used to amplify a total of $0.5 \mu \mathrm{g}$ RNA. Agarose gel electrophoresis was used to separate products and ethidium bromide staining was used for visualization. A Tanon-1000 Gel Image System (Tanon, Shanghai, China) was used to digitize bands and GAPDH was used as the control gene based on previous studies $(5,23)$.

Western blotting. Western blot analysis was performed as previously described (24). Renal tissues were homogenized with ice-cold lysis buffer and were centrifuged at $10,000 \mathrm{x} \mathrm{g}$ for $15 \mathrm{~min}$ at $4^{\circ} \mathrm{C}$. Equal amounts $(100 \mu \mathrm{g})$ of protein were loaded and separated by $10 \%$ SDS-PAGE. Separated proteins were then transferred onto nitrocellulose paper (Bio-Rad Laboratories, Inc., Hercules, CA, USA). A sample of total protein from the lysate $(20 \mu \mathrm{g})$ was separated and blotted. The membranes were incubated with the following primary antibodies: Anti-RAGE (1:250, cat no. MAB1179; R\&D Systems, Inc., Indianapolis, IN, USA), anti-nephrin (1:1,000, cat no. ab58968; Abcam, Cambridge, UK), anti-podocin 
Table I. General data of the rats.

\begin{tabular}{lrccccc}
\hline Group & $\mathrm{n}$ & $\mathrm{FPG}(\mathrm{mmol} / \mathrm{l})$ & $\mathrm{HbA}_{1 \mathrm{C}}(\%)$ & $\mathrm{Ccr}(\mathrm{ml} / \mathrm{min})$ & $\begin{array}{c}\text { Urinary albumin } \\
\text { excretion } 24 \mathrm{~h}(\mathrm{mg})\end{array}$ & $\begin{array}{c}\text { Kidney weight/body } \\
\text { weight }\left(\mathrm{x} 10^{-3}\right)\end{array}$ \\
\hline $\mathrm{C}$ & 10 & $6.98 \pm 0.86$ & $5.60 \pm 0.73$ & $1.98 \pm 0.32$ & $10.22 \pm 1.67$ & $3.34 \pm 0.18$ \\
$\mathrm{CT}$ & 10 & $6.60 \pm 0.81$ & $5.56 \pm 0.71$ & $2.11 \pm 0.74$ & $11.37 \pm 1.08$ & $3.24 \pm 0.18$ \\
$\mathrm{DM}$ & 8 & $23.04 \pm 0.93^{\mathrm{a}}$ & $11.41 \pm 2.14^{\mathrm{a}}$ & $5.11 \pm 1.14^{\mathrm{a}}$ & $24.96 \pm 2.56^{\mathrm{a}}$ & $5.48 \pm 0.17^{\mathrm{a}}$ \\
T & 12 & $21.22 \pm 1.12^{\mathrm{a}}$ & $8.71 \pm 3.54^{\mathrm{a}}$ & $2.80 \pm 1.23^{\mathrm{b}, \mathrm{c}}$ & $15.15 \pm 3.27^{\mathrm{a}, \mathrm{c}}$ & $4.30 \pm 0.17^{\mathrm{a}, \mathrm{c}}$ \\
\hline
\end{tabular}

Mean \pm standard deviation. ${ }^{\mathrm{a}} \mathrm{P}<0.01$ and ${ }^{\mathrm{b}} \mathrm{P}<0.05$ vs. $\mathrm{C}$ group; ${ }^{\mathrm{c}} \mathrm{P}<0.01$ vs. DM group. FPG, fasting plasma glucose; HbA ${ }_{1 \mathrm{C}}$, hemoglobin $\mathrm{A} 1 \mathrm{c} ; \mathrm{Ccr}$, endogenous creatinine clearance rate; $\mathrm{C}$, normal kidney; $\mathrm{CT}$, normal rats treated with grape seed proanthocyanidin extracts $\left(250 \mathrm{mg} \cdot \mathrm{kg}^{-1} \cdot \mathrm{day}^{-1}\right)$; $\mathrm{DM}$, diabetes mellitus rats; $\mathrm{T}$, diabetes mellitus rats treated with grape seed proanthocyanidin extracts $\left(250 \mathrm{mg} \cdot \mathrm{kg}^{-1} \cdot \mathrm{day}^{-1}\right)$.

(1:1,000, cat no. sc-21009; Santa Cruz Biotechnology, Inc., Santa Cruz, CA, USA) and anti- $\beta$-actin (1:500, cat no. ab8226; Abcam) overnight at $4^{\circ} \mathrm{C}$, and then reacted with anti-rabbit IgG horseradish peroxidase-conjugated secondary antibodies (1:5,000, cat no. sc-2004; Santa Cruz Biotechnology, Inc.) at room temperature for $1.5 \mathrm{~h}$. Signal detection was performed via exposure of the blot to enhanced diaminobenzidenecolor reagents (OriGene Technologies, Inc., Rockville, MD, USA) for $5 \mathrm{~min}$. Quantification of the luminosity of each identified protein band was performed using Adobe Photoshop software (AdobePhotoshop 7.0; Adobe Systems, Inc., San Jose, CA, USA).

Immunohistochemical study. Renal tissue sections (4 $\mu \mathrm{m})$ were subjected to immunohistochemical staining based on the published method with specific antibodies anti-RAGE (1:100, ab37647; Abcam), anti-nephrin (1:500, ab58968; Abcam), and anti-podocin (1:400, H-130, sc-21009; Santa Cruz Biotechnology, Inc.) (25). Color was developed by incubating with diaminobenzidine and counterstaining with hematoxylin. Controls were obtained by replacing the primary antibody with PBS. Semi quantitative analysis of the percentage of positive staining area in the glomeruli and tubules was evaluated using a computer imaging analysis system (Image-Pro Plus software version 4.5; Media Cybernetics, Inc., Rockville, MD, USA). The brown areas were judged as positive.

Statistical analysis. Data were presented as the mean \pm standard deviation. One way analysis of variance or the Mann-Whitney $\mathrm{U}$ test was performed to compare the differences between groups. $\mathrm{P}<0.05$ was considered to indicate a statistically significant difference.

\section{Results}

Changes of renal function and general parameters. There were four treatment groups, the control group (C group) that received no treatment, rats treated with $250 \cdot \mathrm{mg} \cdot \mathrm{kg}^{-1} \cdot \mathrm{day}^{-1}$ GSPE (CT group), rats that received STZ injection to induce diabetes, however no additional treatment (DM group) and rats that were diabetic but received $250 \cdot \mathrm{mg} \cdot \mathrm{kg}^{-1} \cdot \mathrm{day}^{-1} \mathrm{GSPE}$ ( $\mathrm{T}$ group). Rats in each group were observed from 1 week to 24 weeks. At the start of the experiment, there were 12 rats in each of the $\mathrm{C}$ and $\mathrm{CT}$ groups and 15 rats in each of the $\mathrm{T}$
Table II. Alterations in serum AGE levels in rats.

\begin{tabular}{lrc}
\hline Group & $\mathrm{n}$ & AGEs \\
\hline C & 10 & $0.0182 \pm 0.0005$ \\
CT & 10 & $0.0221 \pm 0.0063$ \\
DM & 8 & $0.0351 \pm 0.0021^{\mathrm{a}}$ \\
T & 12 & $0.0276 \pm 0.0054^{\mathrm{b}}$ \\
\hline
\end{tabular}

Data are presented as the mean \pm standard deviation. All animals injected with streptozotocin exhibited a high level of AGEs in serum compared with $\mathrm{C}$ group ( $\left.{ }^{\mathrm{a}} \mathrm{P}<0.01\right)$. Diabetic rats treated with GSPE (T group) had lower AGEs compared with DM group $\left({ }^{\mathrm{b}} \mathrm{P}<0.01\right)$. AGEs, advanced glycation end products; $\mathrm{C}$, normal kidney; $\mathrm{CT}$, normal rats treated with grape seed proanthocyanidin extracts $\left(250 \mathrm{mg} \cdot \mathrm{kg}^{-1} \cdot \mathrm{day}^{-1}\right)$; $\mathrm{DM}$, diabetes mellitus rats; $\mathrm{T}$, diabetes mellitus rats treated with grape seed proanthocyanidin extracts $\left(250 \mathrm{mg} \cdot \mathrm{kg}^{-1} \cdot \mathrm{day}^{-1}\right)$.

and DM groups. At the end of the experiment, there were 10, 10,8 , and 12 surviving rats in the $\mathrm{C}, \mathrm{CT}, \mathrm{DM}$ and $\mathrm{T}$ groups, respectively. As presented in Table I, the FPG, $\mathrm{HbA}_{1 \mathrm{C}}, 24 \mathrm{~h}$ urinary albumin excretion, $\mathrm{Ccr}$ and ratio of kidney weight to body weight in the DM group were significantly increased compared with the $\mathrm{C}$ group $(\mathrm{P}<0.01)$. The diabetic rats treated with GSPE (T group) had markedly reduced Ccr, urinary albumin excretion $(\mathrm{P}<0.01)$, and ratio of kidney weight to body weight than that of the DM group. However, no significant differences in FPG and $\mathrm{HbA}_{1 \mathrm{C}}$ were identified between the DM and the T groups.

Changes in serum AGE levels. As presented in Table II, animals that were injected with STZ exhibited a significantly higher level of AGEs in serum than that in the $C$ group $(\mathrm{P}<0.01)$. Diabetic rats that were treated with GSPE ( $\mathrm{T}$ group) had significantly lower AGEs than the level in the DM group $(\mathrm{P}<0.01)$.

Renal morphological changes. The PAS-staining results in the glomeruli of each group are presented in Fig. 1A. Quantitative analysis of the percentage of the PAS-positive area in the glomeruli is summarized in Fig. 1B. The ECM accumulation was significantly higher in the glomeruli of the DM group than that of the $\mathrm{C}$ group $(\mathrm{P}<0.01)$, and diabetic rats treated with 
A
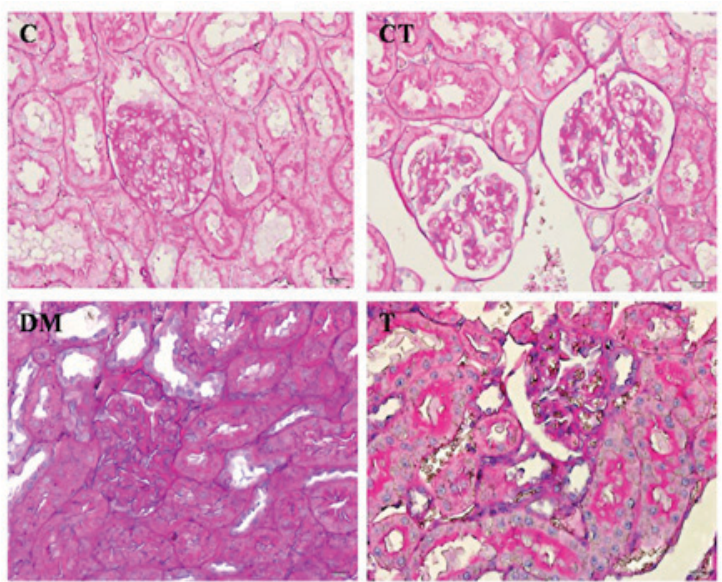

B

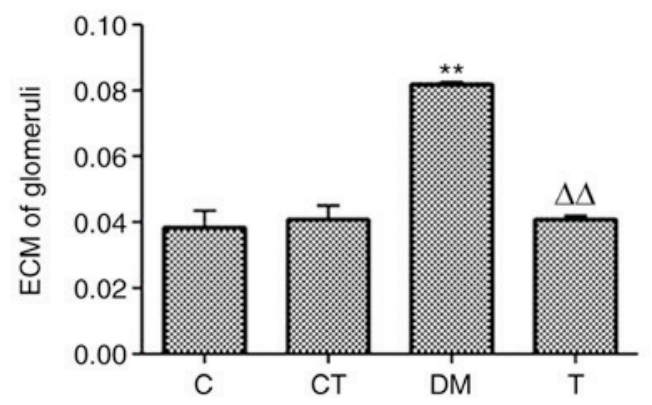

Figure 1. (A) Light microscopic images of renal morphological changes in rats by PAS (PAS, magnification $\mathrm{x} 400$ ). ECM accumulation in DN rat kidneys by PAS staining. C, normal kidney; $\mathrm{CT}$, normal rats treated with GSPE $\left(250 \mathrm{mg} \cdot \mathrm{kg}^{-1} \cdot \mathrm{day}^{-1}\right)$; DM, DM rats; T, DM rats treated with GSPE $\left(250 \mathrm{mg} \cdot \mathrm{kg}^{-1} \cdot \mathrm{day}^{-1}\right)$. (B) Analysis of ECM in glomeruli by PAS staining. Higher ECM accumulation was observed in the kidneys of DM group rats compared with that of the $\mathrm{C}$ group $\left({ }^{* *} \mathrm{P}<0.01\right.$ vs. C) Lower ECM accumulation was observed in the kidneys of the $\mathrm{T}$ group rats compared with the DM group $\left({ }^{\Delta} \mathrm{P}<0.01\right.$ vs. DM). ECM, extracellular matrix; $\mathrm{DN}$, diabetic nephropathy; PAS, periodic acid-Schiff; DM, diabetes mellitus; GSPE, grape seed proanthocyanidin extracts.

GSPE (T group) had a significantly lower ECM accumulation in the glomeruli than that of the DM group $(\mathrm{P}<0.01)$.

Electron microscopic observations. The foot processes of glomeruli were broader and flatter in the DM group than that in the other groups. It was also identified that the mean FPW was significantly greater in diabetic glomeruli as compared with control glomeruli $(\mathrm{P}<0.01)$. The mean slit pore length was significantly shorter in diabetic glomeruli than that of the control glomeruli $(\mathrm{P}<0.01)$. Additionally, there were significantly fewer slit pores (per $100 \mu \mathrm{m}$ ) of GBM in diabetic glomeruli than in the control glomeruli $(\mathrm{P}<0.01)$. The GBM was significantly thicker in diabetic glomeruli as compared with control glomeruli $(\mathrm{P}<0.01)$. However, these changes were significantly reversed by GSPE treatment (Fig. 2 and Table III).

Renal expression of RAGE, nephrin, and podocin by RT-PCR and western blotting. In the kidney cortex of DM rats, the mRNA and protein expression of RAGE were markedly increased compared with the levels in the $\mathrm{C}$ group $(\mathrm{P}<0.01)$, and GSPE treatment significantly decreased the expression of RAGE (P<0.01) (Figs. 3 and 4). A significantly decreased expression of nephrin mRNA and protein was observed in the DM group as compared with the $\mathrm{C}$ group $(\mathrm{P}<0.05$ and $\mathrm{P}<0.01$, respectively), and GSPE treatment significantly increased the mRNA expression and protein level of nephrin $(\mathrm{P}<0.05$ and $\mathrm{P}<0.01$, respectively) (Figs. 3 and 4). However, no significant differences were identified in the mRNA or protein expression of podocin among the four groups ( $\mathrm{P}>0.05)$ (Figs. 3 and 4).

Immunohistochemical staining for RAGE, nephrin, and podocin protein in glomeruli. Immunohistochemical staining indicated the localization of signals for RAGE, nephrin and podocin predominantly in the glomeruli. The intensity and area of RAGE staining were significantly increased in the glomeruli of diabetic rats as compared with the $\mathrm{C}$ group, and GSPE treatment significantly reversed this effect (Fig. 5A). The intensity and area of nephrin staining were significantly decreased in the glomeruli of diabetic rats compared with the $\mathrm{C}$ group, and GSPE treatment also significantly reversed these effects (Fig. 5B). No differences were observed in the intensity and area of podocin staining in the glomeruli for the four groups (Fig. 5C).

\section{Discussion}

The incidence of diabetic nephropathy is increasing worldwide, and identification of associated molecular changes is important for prevention and treatment $(1,2)$. Among the three intrinsic cells in the glomerulus, podocytes have special physiological functions and cytobiological traits (26).


Figure 2. Electron microscopic images of renal microstructure changes in rats (magnification, x15,000). GSPE treatment decreased STZ-induced renal ultrastructural abnormalities. (Original magnification x15,000.) GSPE, grape seed proanthocyanidin extracts; BM, basement membrane; PC, podocyte; End, endothelial cell; FP, foot processes; Mes, mesangial cell; Go, golgi apparatus; RBC, red blood cell. 
Table III. Electron microscopic findings in the four groups.

\begin{tabular}{lccc}
\hline Parameter & C & DM & T \\
\hline$n$ & 10 & $404.5 \pm 20.7^{\mathrm{a}}$ & 12 \\
Foot process width (nm) & $296.2 \pm 10.5$ & $26.2 \pm 3.2^{\mathrm{a}}$ & $353.9 \pm 18.4^{\mathrm{b}}$ \\
Slit pore length (nm) & $32.5 \pm 2.6$ & $181.5 \pm 12.1^{\mathrm{a}}$ & $30.6 \pm 3.4^{\mathrm{b}}$ \\
Number of slit pores (per $100 \mu \mathrm{m})$ & $256.3 \pm 13.2$ & $270.2 \pm 29.8^{\mathrm{a}}$ & $239.2 \pm 13.5^{\mathrm{b}}$ \\
GBM thickness (nm) & $165.8 \pm 20.5$ & $190.3 \pm 22.3^{\mathrm{b}}$
\end{tabular}

Data are presented as the mean \pm standard deviation. ${ }^{\mathrm{a}} \mathrm{P}<0.01 \mathrm{vs}$. $\mathrm{C}$ group; ${ }^{\mathrm{b}} \mathrm{P}<0.01 \mathrm{vs}$. DM group. $\mathrm{C}$, normal kidney; $\mathrm{CT}$, normal rats treated with grape seed proanthocyanidin extracts $\left(250 \mathrm{mg} \cdot \mathrm{kg}^{-1} \cdot \mathrm{day}^{-1}\right)$; DM, diabetes mellitus rats; $\mathrm{T}$, diabetes mellitus rats treated with grape seed proanthocyanidin extracts $\left(250 \mathrm{mg} \cdot \mathrm{kg}^{-1} \cdot \mathrm{day}^{-1}\right)$; GBM, glomerular basement membrane.
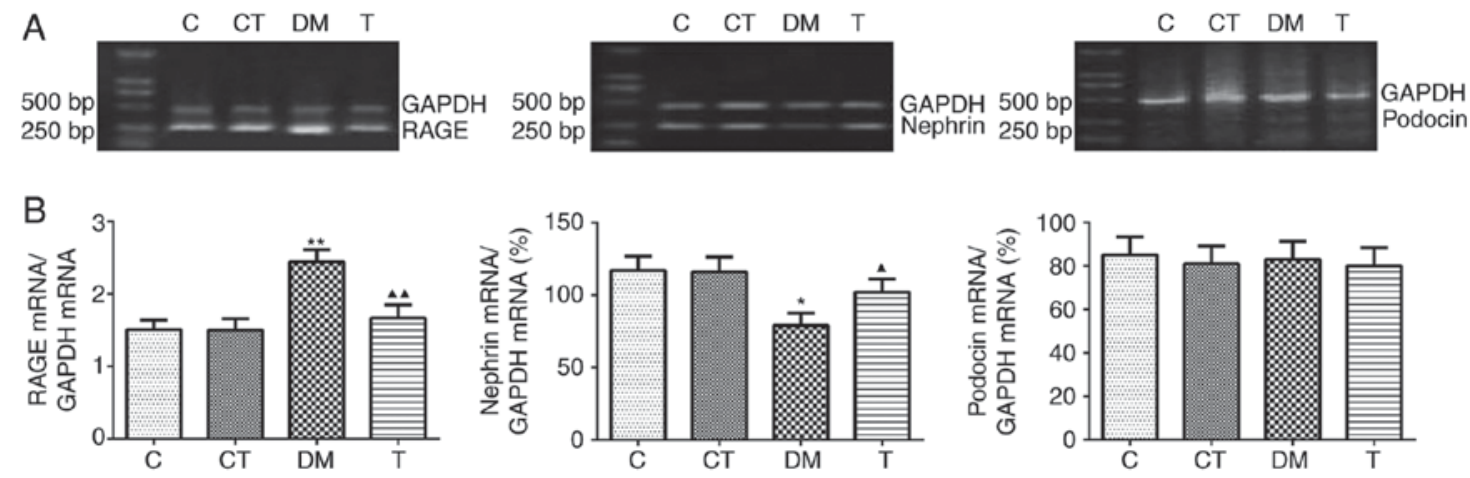

Figure 3. (A) Expression of renal RAGE, nephrin, and podocin measured byreverse transcription-polymerase chain reaction (B) Renal RAGE was significantly decreased in the kidneys of the T group rats compared with the DM group $\left({ }^{\Delta} \mathrm{P}<0.01 \mathrm{vs}\right.$. DM) and renal nephrin was significantly increased in the kidneys of $\mathrm{T}$ group rats compared with the DM group ( ${ }^{(} \mathrm{P}<0.05$ vs. DM). RAGE, receptor for advanced glycation end-products; DM, diabetes mellitus; $\mathrm{C}$, normal kidney; $\mathrm{CT}$, normal rats treated with grape seed proanthocyanidin extracts $\left(250 \mathrm{mg} \cdot \mathrm{kg}^{-1} \cdot \mathrm{day}^{-1}\right)$; DM, DM rats; T, DM rats treated with grape seed proanthocyanidin extracts $\left(250 \mathrm{mg} \cdot \mathrm{kg}^{-1} \cdot \mathrm{day}^{-1}\right)$.
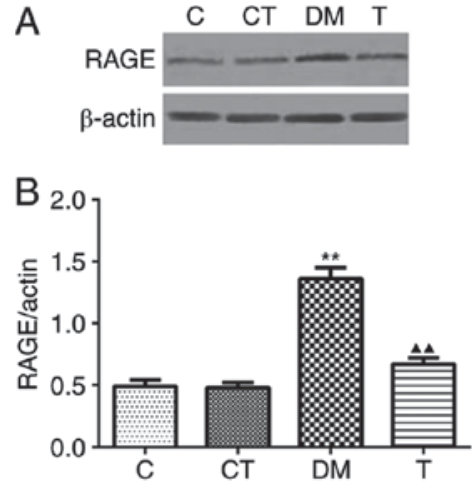

C CT DM T
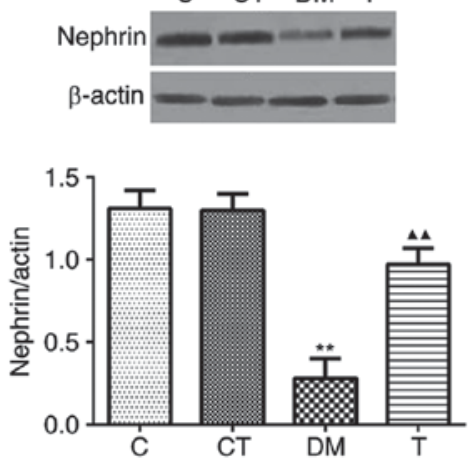

C CT DM T


Figure 4. (A) Expression of RAGE, nephrin, and podocin by western blotting analysis. (B) Renal RAGE was significantly decreased ( ${ }^{\Delta \Delta} \mathrm{P}<0.01 \mathrm{vs}$. DM) and renal nephrin was significantly increased $\left({ }^{\Delta} \mathrm{P}<0.01 \mathrm{vs}\right.$. DM) in the kidneys of T group rats compared with the DM group. RAGE, receptor for advanced glycation end-products; DM, diabetes mellitus; C, normal kidney; CT, normal rats treated with grape seed proanthocyanidin extracts $\left(250 \mathrm{mg} \cdot \mathrm{kg}^{-1} \cdot \mathrm{day}^{-1}\right) ; \mathrm{DM}, \mathrm{DM}$ rats; T, DM rats treated with grape seed proanthocyanidin extracts $\left(250 \mathrm{mg} \cdot \mathrm{kg}^{-1} \cdot \mathrm{day}^{-1}\right)$.

Podocyte damage occurs in the early stage of DN, and this injury to podocytes can cause proteinuria, and accelerate the development of DN (27). The slit diaphragm bridges adjacent foot processes derived from different podocytes and functions as the ultimate molecular size filter. Nephrin serves an important role in the pathogenesis of proteinuria in $\mathrm{DN}$ as a podocyte-associated protein that can comprise the slit diaphragm $(28,29)$. Additionally, proteinuria is closely associated with ultrastructural changes in podocytes in DN. Reduced slit pore length and increased foot process width have been demonstrated in animal models of diabetes in addition to in patients with diabetes $(30,31)$. Berg et al (30) also identified a strong correlation between FPW and urinary albumin excretion inpatients with type 1 diabetes. 
A

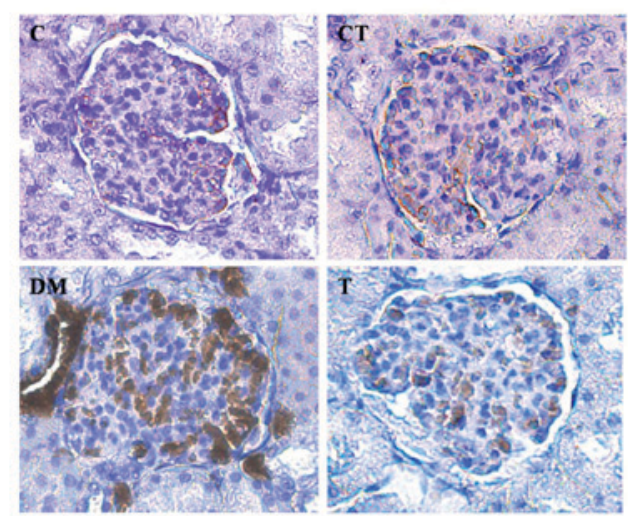

B

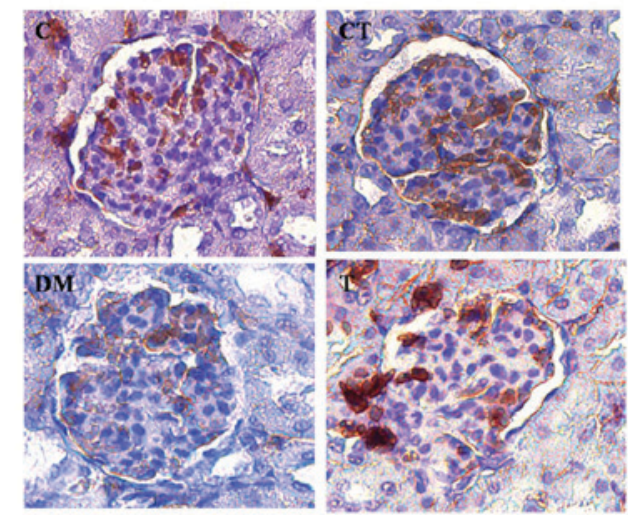

C

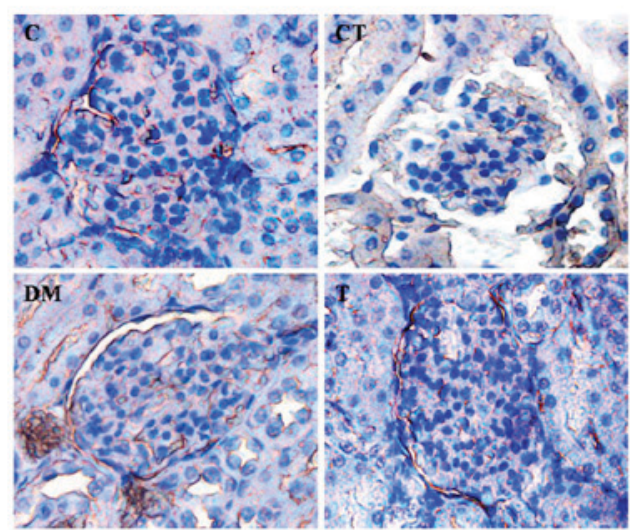

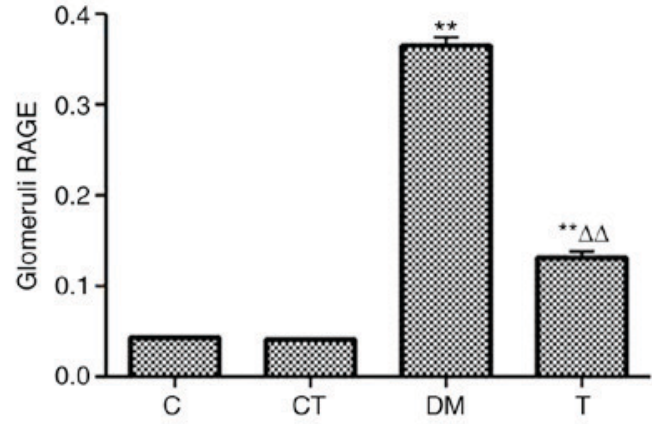
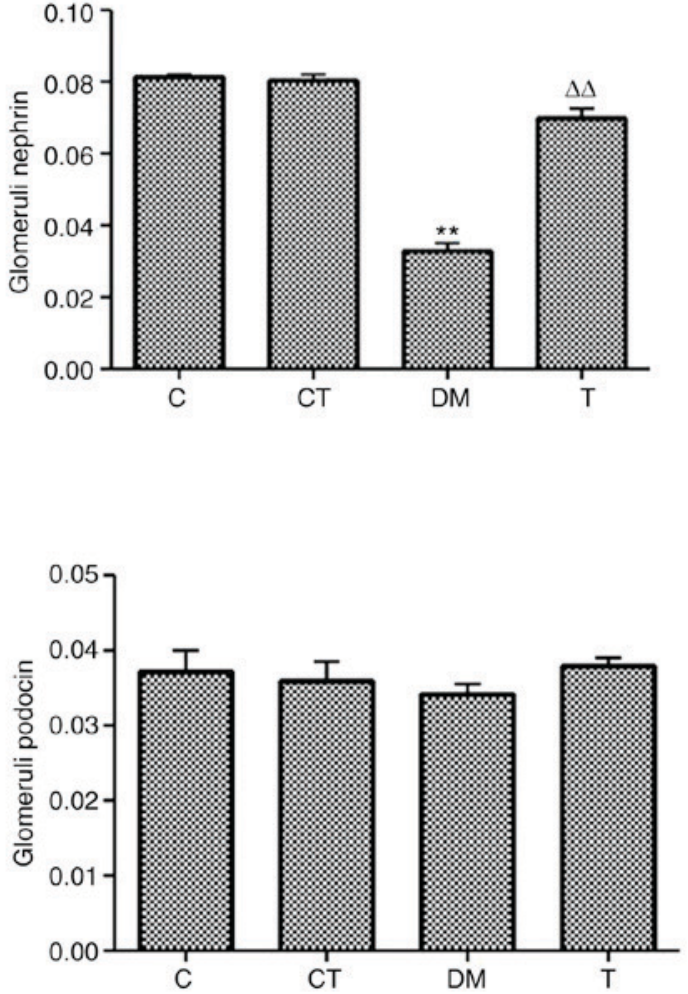

Figure 5. Immunohistochemical staining for RAGE, nephrin, and podocin in glomeruli (ABC; magnification, $x 400$ ). (A) RAGE protein expression was significantly reduced in the kidneys of $\mathrm{T}$ group rats compared with the $\mathrm{DM}$ group $\left({ }^{\Delta \Lambda} \mathrm{P}<0.01 \mathrm{vs}\right.$. DM; ${ }^{*} \mathrm{P}<0.01 \mathrm{vs}$. C). (B) Protein expression of nephrin was significantly increased in the kidneys of $\mathrm{T}$ group rats compared with those in the $\mathrm{DM}$ group $\left({ }^{\Delta} \mathrm{P}<0.01 \mathrm{vs}\right.$. $\mathrm{DM} ;{ }^{*} \mathrm{P}<0.01$ vs. C). (C) Protein expression of podocin were unchanged in the four groups $(\mathrm{P}>0.05)$. RAGE, receptor for advanced glycation end-products; $\mathrm{C}$, normal kidney; $\mathrm{CT}$, normal rats treated with grape seed proanthocyanidin extracts $\left(250 \mathrm{mg} \cdot \mathrm{kg}^{-1} \cdot \mathrm{day}^{-1}\right)$; DM, DM rats; T, DM rats treated with grape seed proanthocyanidin extracts $\left(250 \mathrm{mg} \cdot \mathrm{kg}^{-1} \cdot \mathrm{day}^{-1}\right)$.

In the present study, the $\mathrm{HbA}_{1 \mathrm{C}}, 24 \mathrm{~h}$ urinary albumin excretion, Ccr, and ratio of kidney weight to body weight in DM group were significantly higher than in the $\mathrm{C}$ group. The electron microscopic analysis demonstrated that the foot processes of glomeruli in the DM group were broader and flatter than that of the other groups. In diabetic glomeruli, the FPW was significantly greater, the mean slit pore length was significantly shorter, the number of slit pores (per $100 \mu \mathrm{m}$ ) of GBM was significantly fewer and the GBM was significantly thicker as compared with control glomeruli. Notably, the current study observed that GSPE treatment significantly reversed these morphological changes. Additionally, markedly reduced Ccr, urinary albumin excretion and ratio of kidney weight to body weight were observed in the $\mathrm{T}$ group relative to that of the DM group. These results suggested that GSPE can decrease proteinuria and aid in the maintenance podocyte microstructure.

In order to explore the underlying mechanism of GSPE action, the effects on the podocyte-associated molecules nephrin and podocin were examined. The results indicated that expression of nephrin was significantly decreased, however the expression of podocin was unchanged in diabetic rats, which was also observed in a previous study (32). GSPE treatment significantly increased the expression of nephrin in 
the diabetic rats. These results suggested that the mechanism by which GSPE decreases proteinuria may be associated with the improved expression of nephrin.

AGEs have been documented to serve an important role in stimulating growth factor and cytokine synthesis, which contributes to the pathogenesis of DN (33). RAGE-dependent mechanisms are likely to be responsible for the AGE-induced tissue damage and dysfunction. In vivo study in RAGE-overexpressing diabetic mice observed that interaction between AGEs and their receptor is important in the development of DN (24). AGE-RAGE interactions may lead to diabetic vascular derangement, or trigger and promote the development of renal lesions (24). Additionally, a previous study suggested that, in a mouse model of DN, inactivation of the RAGE gene results in significant suppression of kidney changes, including increased glomerular cell number, advanced glomerulosclerosis, kidney enlargement, mesangial expansion, increased albuminuria, and increased serum creatinine compared with wild-type diabetic mice (34). Importantly, a recent study indicated that blockade of RAGE using a neutralizing antibody prevented the loss of nephrin expression induced by glycated albumin (GA), suggesting the involvement of this receptor in mediating the effect of GA on nephrin expression (35). In the present study, in diabetic rats, markedly higher AGEs and increased expression of RAGE were observed in the DM group relative to the $\mathrm{C}$ group.

However, diabetic rats treated with GSPE had lower serum AGEs and decreased expression of RAGE. The inhibition by GSPE of AGEs formation may be associated with the antioxidative activities of GSPE (17). The oxidation system has been documented to serve an important role in the formation of AGEs $(8,33,35)$. GSPE increases the renal antioxidative ability, decreases NO levels and decreases the activity of NOS in kidney and serum (16). GSPE decreased RAGE mRNA and protein expression in diabetic rats in the present study, which also contributed to the improvement of renal function. It has been reported that AGE can activate the RAGE gene through $N F-\kappa B$ and AGEs accumulation (11). Thus, the action of GSPE to decrease RAGE is associated with the GSPE's inhibition of AGE formation. The in vitro experiments suggest at least two possible mechanisms of nephrin alteration in diabetic conditions, the first mediated by GA-RAGE interaction involving the inhibition of nephrin gene transcription, and the second associated with a rapid redistribution and shedding from the cell surface that depends on Ang II stimulation of the cell cytoskeleton $(35,36)$. A previous study indicated that GA inhibited nephrin synthesis through the engagement of the receptor for AGEs, whereas angiotensin II acted on cytoskeleton redistribution, inducing the shedding of nephrin in proteinuric patients with diabetes (37). The results are consistent with an inhibitory effect of GSPE on the AGEs/RAGE system, which results in increased nephrin expression and decreased proteinuria.

In summary, the results demonstrated that GSPE has a protective effect on kidney in STZ-induced diabetic rats by decreasing urinary albumin excretion and reversing renal pathological damage. The underlying mechanism is associated with the decreased expression of the AGEs/RAGE axis and the increased expression of nephrin in DN rats. Based on these results, it is suggested that GSPE may be a promising therapeutic approach for the prevention and treatment of DN.

\section{Acknowledgements}

The authors would like to thank Dr Xueqing Gao from the Institute of Medical Science (Jinan, China) for the technical assistance, and Mr David Henry (World International English of Jinan, USA) for revising the paper.

\section{References}

1. Collins AJ, Kasiske B, Herzog C, Chavers B, Foley R, Gilbertson D, Grimm R, Liu J, Louis T, Manning W, et al: United States Renal Data System 2005 Annual Data Report Abstract. Am J Kidney Dis 57: A8, 2011

2. Zhang Y, Xiao HQ, Wang Y, Yang ZS, Dai LJ and Xu YC: Differential expression and therapeutic efficacy of microRNA-346 in diabetic nephropathy mice. Exp Ther Med 10: 106-112, 2015.

3. Bhatt K, Lanting LL, Jia Y, Yadav S, Reddy MA, Magilnick N, Boldin $M$ and Natarajan R: Anti-inflammatory role of microRNA-146a in the pathogenesis of diabetic nephropathy. J Am Soc Nephrol 27: 2277-2288, 2016.

4. Wolf G and Ziyadeh FN: Cellular and molecular mechanisms of proteinuria in diabetic nephropathy. Nephron Physiol 106: p26-p31, 2007.

5. Kim JJ, Li JJ, Jung DS, Kwak SJ, Ryu DR, Yoo TH, Han SH, Choi HY, Kim HJ, Han DS and Kang SW: Differential expression of nephrin according to glomerular size in early diabetic kidney disease. J Am Soc Nephrol 18: 2303-2310, 2007.

6. Welsh GI and Saleem MA: Nephrin-signature molecule of the glomerular podocyte? J Pathol 220: 328-337, 2009.

7. Daroux M, Prévost G, Maillard-Lefebvre H, Gaxatte C, D'Agati VD, Schmidt AM and Boulanger E: Advanced glycation end-products: Implications for diabetic and non-diabetic nephropathies. Diabetes Metab 36: 1-10, 2010.

8. Fukami K, Yamagishi S, Ueda S and Okuda S: Role of AGEs in diabetic nephropathy. Curr Pharm Des 14: 946-952, 2008.

9. Park CH, Noh JS, Fujii H, Roh SS, Song YO, Choi JS, Chung HY and Yokozawa T: Oligonol, a low-molecular-weight polyphenol derived from lychee fruit, attenuates gluco-lipotoxicity-mediated renal disorder in type 2 diabetic $\mathrm{db} / \mathrm{db}$ mice. Drug Discov Ther 9: 13-22, 2015.

10. Suzuki D, Toyoda M, Yamamoto N, Miyauchi M, Katoh M, Kimura M, Maruyama M, Honma M, Umezono T and Yagame M: Relationship between the expression of advanced glycation end-products (AGE) and the receptor for AGE (RAGE) mRNA in diabetic nephropathy. Intern Med 45: 435-441, 2006.

11. Ramasamy R, Yan SF and Schmidt AM: Receptor for AGE (RAGE): Signaling mechanisms in the pathogenesis of diabetes and its complications. Ann N Y Acad Sci 1243: 88-102, 2011

12. Yamagishi S: Role of advanced glycation end products (AGEs) and receptor for AGEs (RAGE) in vascular damage in diabetes. Exp Gerontol 46: 217-224, 2011.

13. Kaida Y, Fukami K, Matsui T, Higashimoto Y, Nishino Y, Obara N, Nakayama Y, Ando R, Toyonaga M, Ueda S, et al: DNA aptamer raised against AGEs blocks the progression of experimental diabetic nephropathy. Diabetes 62: 3241-3250, 2013.

14. Thallas-Bonke V, Coughlan MT, Tan AL, Harcourt BE, Morgan PE, Davies MJ, Bach LA, Cooper ME and Forbes JM: Targeting the AGE-RAGE axis improves renal function in the context of a healthy diet low in advanced glycation end-product content. Nephrology (Carlton) 18: 47-56, 2013.

15. Zhai O, Zhong N, Gao HQ, Li BY and Jiang B: Grape seed proanthocyanidins extracts promote apolipoprotein A-I mRNA expression in HepG2 cells under experimental sugar and high-sugar conditions. Eur Rev Med Pharmacol Sci 16: 299-304, 2012.

16. Okudan N, Barışkaner H, Gökbel H, Sahin AS, Belviranlı M and Baysal H: The effect of supplementation of grape seed proanthocyanidin extract on vascular dysfunction in experimental diabetes. J Med Food 14: 1298-1302, 2011.

17. Mansouri E, Panahi M, Ghaffari MA and Ghorbani A: Effects of grape seed proanthocyanidin extract on oxidative stress induced by diabetes in rat kidney. Iran Biomed J 15: 100-106, 2011. 
18. Liang Y, Qiu J, Gao HQ and Li BY: Protective effect of grape seed proanthocyanidins extracts on reperfusion arrhythmia in rabbits. J Nutr Sci Vitaminol (Tokyo) 55: 223-230, 2009.

19. Makita Z, Vlassara H, Cerami A and Bucala R: Immunochemical detection of advanced glycosylation end products in vivo. J Biol Chem 267: 5133-5138, 1992.

20. Lahdenkari AT, Lounatmaa K, Patrakka J, Holmberg C, Wartiovaara J, Kestilä M, Koskimies $\mathrm{O}$ and Jalanko H: Podocytes are firmly attached to glomerular basement membrane in kidneys with heavy proteinuria. J Am Soc Nephrol 15: 2611-2618, 2004.

21. Koop K, Eikmans M, Baelde HJ, Kawachi H, De Heer E, Paul LC and Bruijn JA: Expression of podocyte-associated molecules in acquired human kidney diseases. J Am Soc Nephrol 14: 2063-2071, 2003.

22. Osawa G, Kimmelstiel P and Seiling V: Thickness of glomerular basement membranes. Am J Clin Pathol 45: 7-20, 1966.

23. Lam S, van der Geest RN, Verhagen NA, van Nieuwenhoven FA, Blom IE, Aten J, Goldschmeding R, Daha MR and van Kooten C: Connective tissue growth factor and igf-I are produced by human renal fibroblasts and cooperate in the induction of collagen production by high glucose. Diabetes 52: 2975-2983, 2003.

24. Yamamoto Y, Kato I, Doi T, Yonekura H, Ohashi S, Takeuchi M, Watanabe T, Yamagishi S, Sakurai S, Takasawa S, et al: Development and prevention of advanced diabetic nephropathy in RAGE-overexpressing mice. J Clin Invest 108: 261-268, 2001.

25. Toyoda M, Suzuki D, Umezono T, Uehara G, Maruyama M, Honma M, Sakai T and Sakai H: Expression of human nephrin mRNA in diabetic nephropathy. Nephrol Dial Transplant 19: 380-385, 2004

26. Reddy GR, Kotlyarevska K, Ransom RF and Menon RK: The podocyte and diabetes mellitus: Is the podocyte the key to the origins of diabetic nephropathy? Curr Opin Nephrol Hypertens 17: 32-36, 2008.

27. Lee EY, Kim GT, Hyun M, Kim S, Seok S, Choi R, Lee MY and Chung $\mathrm{CH}$ : Peroxisome proliferator-activated receptor- $\delta$ activation ameliorates albuminuria by preventing nephrin loss and restoring podocyte integrity in type 2 diabetes. Nephrol Dial Transplant 27: 4069-4079, 2012.
28. Kobayashi R, Kamiie J, Yasuno K, Ogihara K and Shirota K: Expression of nephrin, podocin, $\alpha$-actinin- 4 and $\alpha 3$-integrin in canine renal glomeruli. J Comp Pathol 145: 220-225, 2011.

29. Hussain S, Romio L, Saleem M, Mathieson P, Serrano M, Moscat J, Diaz-Meco M, Scambler P and Koziell A: Nephrin deficiency activates NF-kappaB and promotes glomerular injury. J Am Soc Nephrol 20: 1733-1743, 2009.

30. Berg UB, Torbjörnsdotter TB, Jaremko G and Thalme B: Kidney morphological changes in relation to long-term renal function and metabolic control in adolescents with IDDM. Diabetologia 41: 1047-1056, 1998.

31. Mifsud SA, Allen TJ, Bertram JF, Hulthen UL, Kelly DJ, Cooper ME, Wilkinson-Berka JL and Gilbert RE: Podocyte foot process broadening in experimental diabetic nephropathy: Amelioration with renin-angiotensin blockade. Diabetologia 44: 878-882, 2001.

32. Schermer B and Benzing T: Lipid-protein interactions along the slit diaphragm of podocytes. J Am Soc Nephrol 20: 473-478, 2009.

33. Tan AL, Forbes JM and Cooper ME: AGE, RAGE and ROS in diabetic nephropathy. Semin Nephrol 27: 130-143, 2007.

34. Myint KM, Yamamoto Y,Doi T, Kato I,Harashima A, Yonekura H, Watanabe T, Shinohara H, Takeuchi M, Tsuneyama K, et al: RAGE control of diabetic nephropathy in a mouse model: Effects of RAGE gene disruption and administration of low-molecular weight heparin. Diabetes 55: 2510-2522, 2006.

35. Doublier S, Salvidio G, Lupia E, Ruotsalainen V, Verzola D, Deferrari G and Camussi G: Nephrin expression is reduced in human diabetic nephropathy: Evidence for a distinct role for glycated albumin and angiotensin II. Diabetes 52: 1023-1030, 2003.

36. Miyata T and Izuhara Y: Inhibition of advanced glycation end products: An implicit goal in clinical medicine for the treatment of diabetic nephropathy? Ann N Y Acad Sci 1126: 141-146, 2008.

37. Cohen MP, Chen S, Ziyadeh FN, Shea E, Hud EA, Lautenslager GT and Shearman CW: Evidence linking glycated albumin to altered glomerular nephrin and VEGF expression, proteinuria and diabetic nephropathy. Kidney Int 68: 1554-1561, 2005. 